\title{
PRODUTIVISMO: PESQUISA NA UNIVERSIDADE $^{1}$
}

\section{PRODUCTIVISM: RESEARCH AT THE UNIVERSITY}

\author{
Dina Maria Martins Ferreira* \\ UECE
}

Porquê pensar: (...) porque pensar não é tudo. A lucidez das nossas ações [em pesquisa] pressupõe que elas sejam pensadas, mas se forem só pensadas nunca serão ações. (...)

Aqueles que se arrogam a só pensar, passam a vida a espalhar a morte no que escrevem (...)

(Boaventura de Souza Santos)

Resumo: Atualmente, a maneira mais utilizada pelos órgãos avaliadores para julgar a qualidade da produção na universidade é através da quantificação, deixando de lado o aspecto qualitativo. Mede-se a produtividade de um pesquisador pelo número de trabalhos apresentados ou publicados em eventos e revistas de grande relevância no âmbito científico, sem que se considere o impacto do trabalho na área de atuação do seu autor. A busca pelo cumprimento de metas numéricas em um dado período de tempo - chamada por alguns de produtivismo -, torna-se então mais importante que a relevância ou a criatividade dos conhecimentos expostos através da escrita. A análise de fragmentos de Rajagopalan e Einstein vem justamente ratificar a preocupação de alguns cientistas sobre o valor da produção científica, em que se ignora não só o leigo, como também a intervenção da ciência no social.

Palavras-chave: Quantitativo. Qualitativo. Produtivismo. Ciência. Social.

Abstract: Nowadays, the most used way by the evaluating organs to judge the quality of the production in the university is through the quantification, leaving aside the qualitative aspect. The productivity of a researcher is measured by the number of papers presented or published in events and journals of great relevance in the scientific field, without considering the impact of the work in the area of action of its author. The search for the fulfillment of numerical goals in a given period of time - called productivism - then becomes more important than the relevance or creativity of the knowledge exposed through writing. The analysis of the fragments of Rajagopalan and Einstein rightly ratifies the concern of some scientists about the value of scientific production, which ignores not only the layman but also the intervention of science in the social.

Keywords: Quantitative. Qualitative. Productivism. Science. Social.

\author{
${ }^{1}$ Este artigo é parte \\ de pesquisa em \\ que etapas foram \\ publicadas como \\ capítulo de livro, \\ como livro e que \\ agora se adapta às \\ normas da revista \\ Muitas Vozes. \\ * Pesquisadora e \\ professora visitante \\ do Programa de \\ Pós-Graduação em \\ Linguística Aplicada \\ da Universidade \\ Estadual do Ceará \\ e pesquisadora do \\ Centre d'Études \\ sur les Actuel et le \\ Quoditien, Paris \\ V, Sorbonne; $\left(2^{\circ}\right)$ \\ pós-doutoramento \\ em Ciências Sociais \\ pela Université \\ Paris V, Sorbonne, \\ e em Estudos \\ da Linguagem, \\ pela UNICAMP \\ (2009-2010); ( $\left.1^{\circ}\right)$ \\ pós-doutoramento \\ em Pragmática pela \\ UNICAMP (2002- \\ 2003); doutorado pela \\ UFRJ em Linguística \\ (1995); mestrado \\ pela PUC-RJ em \\ Análise do Discurso \\ (1988). Autora de 4 \\ livros; organização \\ de 5 livros; \\ capítulos nacionais e \\ internacionais. Este \\ estudo, adequado \\ e modificado à \\ revista Muitas \\ Vozes, é parte do $2^{\circ}$ \\ pós-doutoramento, \\ publicado em livro \\ (Sujeito Acadêmico \\ - o Rei está nú), em \\ capítulos de livros \\ e apresentado em \\ congressos.
}




\section{Introdução}

Duas questões nos envolvem neste estudo, cujas perspectivas de arvoram de criticidade: pesquisa universitária com foco na práxis social.

No que tange à pesquisa e sua escrita adentramos no gênero acadêmico-científico que surge a partir da necessidade de se divulgar o conhecimento produzido através do método científico. Logo, é imprescindível que a escrita acadêmica esteja sempre vinculada a uma finalidade específica, como trazer algum tipo de avanço para o meio científico: um novo objeto, um olhar criativo sobre um objeto já conhecido, uma metodologia inovadora, enfim, uma discussão que exija sua exposição (artigos, banners, dissertações, teses, etc). Ocorrendo dessa maneira, o resultado seria uma produção escrita criativa que promoveria o desenvolvimento da ciência e o aprimoramento do meio acadêmico.

No Brasil, a produção científica está intrinsecamente ligada à Universidade, pública, o que significa que boa parte do financiamento dado à pesquisa é de origem estatal e federal, de arrecadação de tributos. Faz-se necessário, por isso, que os trabalhos de pesquisadores e instituições mantidos pelo financiamento público sejam avaliados por órgãos responsáveis pelo desenvolvimento científico (tais como a CAPES, o CNPq, FUNCAP, FAPESP $^{2}$, entre outros), para que se conheça a qualidade da produção acadêmica e se mensure os resultados dos investimentos realizados.

Porém, sabemos que, atualmente, a maneira mais utilizada pelos órgãos avaliadores para julgar a qualidade da produção é através da quantificação, deixando o aspecto qualitativo, muitas vezes, nas mãos das bancas de defesa ou de pareceristas de revistas e eventos. Assim, mede-se a produtividade de um pesquisador pelo número de trabalhos apresentados ou publicados em eventos e revistas de grande relevância no âmbito científico, sem que se considere o impacto do trabalho na área de atuação do seu autor. A busca pelo cumprimento de metas numéricas em um dado período de tempo - chamada por alguns de produtivismo -, torna-se então mais importante que a relevância ou a criatividade dos conhecimentos expostos através da escrita. Não é tão difícil observar casos em que o mesmo trabalho é publicado em eventos diferentes apenas com a alteração do título, uma prática não condenável, mas questionável, a fim de cumprir as metas estabelecidas.

\section{Tensões na produção acadêmica}

O “campo" universitário circunscreve um determinado "habitus" (BOURDIEU, 1984), cujas regras e normas muitas vezes geram tensões, muitas vezes impedidas de serem cumpridas. Por exemplo, como atender a marca numérica de $\mathrm{x}$ artigos exigida pela CAPES, senão por subterfúgios camuflados? Ortega y Gasset (1967, p. 52) pondera que “eu sou eu e minhas circunstâncias”, mas, no entanto, o que ele nos propõe não é nos vitimizarmos,

${ }^{2}$ FUNCAP: Fundação Cearense de Apoio ao Desenvolvimento Científico e Tecnológico; FAPESP: Fundação de Amparo à Pesquisa do Estado de São Paulo, CAPES: Coordenação de Aperfeiçoamento de Pessoal do Ensino Superior, CNPQ: Conselho Nacional de Desenvolvimento Científico. 
mas lutar para salvar nossas circunstâncias, pois "se não salvo a ela, não salvo a mim”. Ao propor que devemos salvar nossas circunstâncias, Ortega y Gasset entende "salvar" como compreender os sentidos de nossas circunstâncias, como se as compreendendo pudéssemos melhor vivê-las e melhor ligá-las, no caso, à nossa prática científica: “para salvar a circunstância é preciso compreendê-la, ou seja, saber o que ela significa nela mesma, na sua unidade e em suas efetivas conexões, em sua irredutibilidade, contudo na plenitude do seu 1998/1999, p. 63).

E, para justamente compreendermos nossas circunstâncias no espaço acadêmico, vamos entrar em um universo conflituoso em que os caminhos do pesquisador se emaranham em uma rede cujos nós políticos oscilam de acordo com os ventos, ou seja, a postura ética do pesquisador que se movimenta entre o aprofundamento na produção do saber e seu direito de refletir, pensar e agir, em contrapartida às exigências lattianas ${ }^{3}$ que valoram o conhecimento pela quantidade de papéis publicados.

Muitos espaços acadêmicos priorizam a quantidade de produção sem levar em conta a qualidade exigida para se alcançar o universo da ciência. No Brasil, tivemos o lançamento em agosto de 1999 da Plataforma Lattes, sistema organizado pelo CNPq que visa gerenciar uma base de dados sobre os pesquisadores e suas produções. Tantas são as solicitações numéricas de produção que o pesquisador, para atender às 'normas', pode estar abrindo mão do aprofundamento do conhecimento. Como postula Waters (2006, p. 28), editor da Harvard University Press, ao explicar o que chama "eclipse do valor”,

Entramos na região sombria da pesquisa acadêmica, e agora as exigências de produtividade estão levando à produção de um número muito maior de coisas sem sentido. Em épocas como esta, pesquisadores inescrupulosos e inebriados fazem alegações falsas sob a aparência de serem interessantes, mas que são também inverificáveis.

A voz cáustica de Waters sobre o que está ocorrendo no campo universitário se amplia ao valorar a produção de artigos:

O problema dos artigos ridículos publicados pelos estudos das humanidades foi em parte resultado do grande aumento do número de publicações que se espera que eles próprios (e todos os acadêmicos) perpetrem em papel ou despejem uns sobre os outros, na forma de comunicações em congressos. Esse quadro mostra um mundo todo errado, mas o problema não se limita às humanidades. Estamos experimentando uma crise generalizada das avaliações, que resulta de expectativas não razoáveis sobre quantos textos um estudioso deve publicar. Não estou dizendo que não haja boas publicações - isso está muito longe de ser o caso -, mas o que as boas publicações têm de bom se perde em meio a tantas produções que são apenas competentes e muitas mais que não são nem isso (WATERS, 2006, p. 24-25).
${ }^{3} \mathrm{O}$ neologismo lattianas - licença estilística - refere-se ao currículo Lattes. 
Em outras palavras, é o que Gonçalves Filho (2007, p.1) também afirma sobre a produção de livros: "o modelo que as universidades adotam para a publicação de livros é o mesmo de uma fábrica de automóveis. Elas exigem produtividade, mas não exatamente qualidade”. E em resenha sobre o livro tão crítico e violento de Waters, outra voz critica a corrida que se estabelece pela publicação:

[...] corrida pela publicação talvez jamais tenha sido tão frenética quanto hoje. Pesquisadores e professores precisam alcançar o estrelato nas avaliações de órgãos do governo, as universidades precisam obter conceitos e notas altas, programas de pós-graduação precisam sustentar suas boas famas e tudo isso depende da produção dos docentes vinculados às instituições. Os currículos, de preferência o Lattes, precisam estar muito bem recheados para que valham algo nessa competição, daí uma explosão de revistas ruins e livros que deveriam ter sido revistas. Um boom de obras organizadas com jeito de coletânea escolar, artigos feitos a partir de dissertações de mestrado e teses de doutorado mal editadas, textos apressados, organizadores esbaforidos tentando aumentar um ou dois pontos na "carteira” (RIBEIRO, 2009, p. 2 ).

Mas pensamos que não é só de gritos desesperados que se desconstrói o que vem ocorrendo com o pesquisador e a produção do conhecimento, porquanto os atuais gritos seriam a ponta do iceberg de um tsunami que já se anunciou há décadas pela voz de Bourdieu (1984). Só que agora está aparecendo que as águas turbulentas do tsunami estão promovendo afogamentos, afinal Bourdieu (1984, p. 21) já proclamava que "não se pode excluir que análise científica, ela mesma, venha a exercer um efeito de teoria própria a transformar a visão comum do campo [acadêmico]” (tradução nossa ${ }^{4}$ ). Aliás, para este autor,

o prestígio científico equivale a um efeito de oficialização, de natureza semi legais: por isso, a criação de classes de notoriedade internacional fundada sobre o número de citações ou a elaboração de um índice de participação no jornalismo são operações semelhantes àquelas que os produtores de palmares realizam no seio do próprio campo (1984, p. 21, tradução nossa ${ }^{5}$, itálicos acrescidos).

Tentando olhar para esta problemática por outras direções, convergentes e/ou divergentes, ela pode ser pensada por outros focos: o valor do sujeito pesquisador frente ao objeto pesquisado e sua importância para o crescimento da ciência com consequente atuação social. Essa questão se amplia se a quantidade alcança o entulho do saber.

Dois fragmentos discursivos são as locomotivas de nossa argumentação: um de Einstein (in TAGEBLATT, 2005) que aponta o desgosto diante do atulhamento de saber; e outro de Rajagopalan (2003) que critica o linguista como um derramador de pérolas. Ambos os fragmentos, de alguma forma,
4 “On ne peut exclure que l'analyse scientifique ellemême vienne à exercer un effet de théorie propre à transformer la vision ordinaire du champ".

5 “(...) le prestige scientifique équivaut, on vient de le voir, à un effet d'officialisation, de nature quasi juridique : ainsi, l'établissement de classes de notoriété internationale fondée sur le nombre de citations ou l'élaboration d'un indice de participation au journalisme sont des opérations tout à fait analogues à celles que réalisent, au sein même du champ, les producteurs de palmarès". 
comungam críticas sobre a questão do amontoado - o primeiro atende a um espaço do saber mais amplo e o segundo a área dos estudos da linguagem:

A comunidade dos pesquisadores é uma espécie de órgão do corpo da humanidade. Esse órgão produz uma substância essencial à vida que deve ser fornecida a todas as partes do corpo, na falta da qual ele perecerá. Isso não quer dizer que cada ser humano deva ser atulhado de saberes eruditos e detalhados, como ocorre frequentemente em nossas escolas nas quais [o ensino das ciências] vai até o desgosto. Não se trata também de o grande público decidir sobre questões estritamente científicas. Mas é necessário que cada ser humano que pensa tenha a possibilidade de participar com toda lucidez dos grandes problemas científicos de sua época, mesmo se sua posição social não lhe permite consagrar uma parte importante de seu tempo e de sua energia à reflexão científica. É somente quando cumpre essa importante missão que a ciência adquire, do ponto de vista social, o direito de existir (EINSTEIN in TAGEBLATT, 2005, p. 4, itálicos acrescidos); e

A autoridade do linguista não é automaticamente aceita pela sociedade ampla. Ela precisa ser conquistada. E para conquistá-la é necessário usar bastante persuasão. Não é derramando o nosso saber - como se fosse um punhado de pérolas em meio a um amontoado de porcos ávidos - que vamos conseguir convencer o público leigo de que temos algo importante a dizer (RAJAGOPALAN, 2003, p. 8), itálicos acrescidos).

No primeiro fragmento Einstein atualiza comentários que perfilam o pesquisador como um profissional que se perde na quantidade de saberes, os quais não atuam na prática social; e, como tal, apenas preenchem dados quantitativos necessários para alçar o profissional à importância curricular solicitada pelo Olimpo acadêmico. No segundo, Rajagopalan completa a problemática do quantitativo ao posicionar o saber na estratosfera dos eleitos que ignoram o saber do leigo; este autor levanta a questão da necessidade dos estudiosos ouvirem os leigos, já que ambos os sujeitos - pesquisador e leigo - compartilham a prática social em que convivem.

No que concerne ao produtivismo quantitativo, o sujeito acadêmico ‘comum' é aquele que normalmente ainda não desfila pelo tapete vermelho da Academia, que não faz parte da casta nobre, e que, por tal, se encontra na massa de um agrupamento acadêmico cujos corpos se movimentam na multidão de objetos do conhecimento valorados pela quantidade. Damos a esse acadêmico a valoração de ‘comum’ não para aplaudir aqueles ‘divinos’, mas para salientar que não estamos atribuindo a todos os acadêmicos a postura que estamos discutindo. Nessa valoração, primeiramente estaria a quantidade de papéis, ou seja, o pesquisador passa a ser avaliado pelo volume de papéis que fabrica; escreve sob a ótica da paráfrase, pois há que enumerar multiplicando 'conhecimento', o que nos faz lembrar a piada de corredor em que o pesquisador ironicamente diz ao colega à sua frente: - se eu ganhasse na proporção de papéis que manejo, estaria rico. A segunda perspectiva do quantitativo é correlacionar a quantidade de escritos 
à quantidade de objetos de saber; a cada escritura, o pesquisador pensa estar criando múltiplos objetos de saber. No entanto, cada produção não é necessariamente um novo objeto de saber, pode ser uma releitura do objeto. Barthes (1974) nos auxilia com a ideia de que cada releitura é uma primeira leitura, ou melhor, ressignificar um texto não é obrigatoriamente apresentar um novo objeto, mas possivelmente reapresentá-lo sob nova ótica. Por esse foco, entramos na terceira valoração do quantitativo, que se avoluma ao propiciar a cada objeto de saber novas representações. O atulhamento do saber ganha um lamento frente a um desejo não realizado:

A tese do representacionalismo ${ }^{6}$ é, ao mesmo tempo, uma lamentação e uma expressão de desejo. Ela é um gesto de lamentação porque afirma a incapacidade dos seres humanos de apreenderem o mundo numenal ${ }^{7}$ tal e qual (...) Por outro lado, ela também é uma expressão de um desejo, pois elege como condição ideal da linguagem a total transparência (RAJAGOPALAN, 2003, p. 31, itálicos acrescidos).

Apesar da questão do representacionalismo se ater à teoria de linguagem, fazemos correlação metafórica às múltiplas representações que o pesquisador dá a seu objeto de pesquisa, que, para provê-lo de aparência de ciência, precisa de derivações representacionais que se agrupam em montes aleatórios. Ele precisa de qualquer maneira que seu objeto se apresente, mas como essa epifania científica nem sempre é possível ou alcançada constrói ilusoriamente um amontoado de representações. Derrida (1999) nos possibilita continuar em nossa metáfora ao oferecer o que chama de "metafísica da presença”. Esse autor aplica a ideia de “metafísica da presença” à escritura, ou seja, nenhum texto pode aspirar a um sentido estável, pois o sentido está sempre em descentramento, na medida em que o rompimento entre significante e significado é constante, ou seja, pensamos que há uma essência do significado, quando apenas temos a ilusão de sua presença. E podemos posicionar o pesquisador nessa mesma dinâmica: ele pensa ser seu objeto de estudo o centro essencial do saber, mas, na realidade, tem à sua frente a ilusão de sua presença, na medida em que nenhum objeto de saber pode aspirar a um significado estável, estando este em contínua reprodutibilidade sem uma identidade unitária e estável. E, nessa busca de eliminar sua representatividade e mostrá-lo em sua essência, pode estar criando um amontoado de representações. Por essa situação, é que formulamos que o desejo de apresentação é o lamento das representações.

Alguns pensadores, inclusive os referidos - Einstein e Rajagopalan -, lutam contra a postura do excesso do sujeito-cientista. Mas parece-nos que este sujeito que se perde em seu amontoado de saber ou que derrama saberes em detalhamentos ‘infinitos’ está situado em um momento sócio-histórico. Ou melhor, em um contexto mais amplo, é necessário entender que o sujeito e seu objeto de saber estão inseridos no momento da pós-modernidade, aquele em que "previamente vivido como tendo uma identidade unificada e
${ }^{6}$ Representacionalismo $\mathrm{da} /$ na linguagem leva à problemática da linguagem como atividade construtora de mundo versus a linguagem separada dos objetos do mundo. Ver Dascal (1983).

${ }^{7}$ Expressão noumenon, utilizada por Kant para determinar a coisa em si. Ver Kant (1978). 
estável, está se tornando fragmentado: composto não de uma única, mas de várias identidades, algumas vezes contraditórias ou não resolvidas” (HALL, 2000, p. 12). O que se pode aventar é que os sujeitos pesquisadores, por estarem na prática social (acadêmica) de uma pós-modernidade, portanto fragmentados, saem em busca de um essencialismo estratégico, que aporta na quantidade aleatória de um pretenso fazer científico. A ideia do excesso quantitativo junta fragmentos do saber que constrói um centro, mesmo que seja um centro atulhado.

Em contexto mais específico, Sennett (2001) talvez nos dê argumentos de discussão - e não de justificativas para a persistência do atulhamento. Para este autor, o sujeito pesquisador motivado cria expectativas - tais como divulgação e reconhecimento - em relação ao objeto pesquisado; como as expectativas não são atendidas, começa a adiar o resultado de suas expectativas; e de tanto adiar cai na fronteira do sujeito irônico, aquele que talvez só acumule papéis, objetos, representações de objeto e até ironize em torno deles - uma forma etnocêntrica de se valorizar, pois reúne os objetos em um monte, um centro atulhado mas não menos centro.

A força etnocêntrica do atulhamento de saberes não se encontra só em uma possível justificativa para satisfação de expectativas e rearrumação de fragmentações em um centro-monte. O etnocentrismo se faz presente na própria crítica contra o atulhamento de saberes. Einstein (in TAGEBLATT, 2005) e Rajagopalan (2003) estão presos ao etnocentrismo, na medida em que ao criticar o amontoado de saber, designam os pesquisadores como “substância essencial” e "pérola”, respectivamente. A aporia se manifesta, pois a crítica precisa do fetiche para combatê-lo: pesquisador e derramador de saber sofrem ação de fetiche, pois são representados no processo designativo como ídolos venerados - "substância essencial” e "pérola”. Sem dúvida, são designações que ratificam a posição etnocêntrica do cientista, cujas designações precisam ser utilizadas na tentativa de romper o etnocentismo. Tais designações tentam deslocar o centro do saber pelo processo de transposição (renversement ${ }^{7}$ ) (DERRIDA, 1999), mas não conseguem desconstruir a oposição binária, já que não basta apenas inverter a dessimetria, porquanto se continua nas oposições binárias: pérola/porco e ciência/ laico. Parece que as categorias - pérola/porco e ciência/laico - habitam a dimensão da (in)discernibilidade, ou seja, (im)possibilidade de decidir entre o falso e o verdadeiro, entre o pior e o melhor, quando talvez a questão entre Olimpo - pesquisadores - e Hades - leigos - seja uma questão do que Derrida (1999) nomeia de 'indecidível', ou seja, marcas são inscritas sem posições decidíveis e sem independência umas das outras.

É importante indicar, em nossa argumentação, que não estamos em nossas indagações criando hostilidades entre nossos pares, pois “não há nada verdadeiro, sábio, humano ou estratégico em confundir hostilidade à
${ }^{7}$ Segundo Derrida (1999), renversement é apontar o que foi recalcado e valorizá-lo; a leitura desconstrutora propõe-se como leitura descentrada e, por isso mesmo, não se reduz ao movimento de renversement, pois se estaria apenas deslocando do centro por inversão, quando a proposição radical é a de anulação do centro como lugar fixo e imóvel. 
injustiça e à opressão, (...) com hostilidade à ciência e à racionalidade, o que é uma tolice” (ALBERT in SOKAL; BRICMONT, 1999, p. 13).

O leitor deve naturalmente estar se perguntando se os abusos de paráfrases, se o volume de produção sem inovação de conhecimento "nascem de uma fraude consciente, de autoengano ou de uma combinação de ambos” (SOKAL; BRICMONT, 1999, p. 20). Essas questões específicas sobre atitude e intenções de determinados pesquisadores não são parte de nossa proposta. Não estamos no embate proposto por Sokal e Bricmont (1999) em relação a intelectuais de renome. A nossa proposta é um 'pensar crítico' sobre a postura acadêmica do pesquisador não apenas em relação ao saber, mas ainda em relação ao modelo de produtividade imposto pela Academia e à escrita resultante dessa prática.

\section{Das tensões à guerra de sobrevivência}

É na obra A república dos bons sentimentos, de Michel Maffesoli (2009, p. 9), que encontramos a passagem da tensão à guerra de sobrevivência do acadêmico:

Do que não há dúvida é que essa intelligentsia parece ter medo de pensar. Ou, pelo menos, que ela não considera que pensar seja algo essencial, preferindo se contentar com dogmas ideológicos e outras certezas teóricas. Essa constatação, um tanto abrupta, vale para vários países do mundo (itálicos no original).

Este pensador ironicamente, chama o habitat dos acadêmicos de “república”, que segundo Platão seria o local dos justos e bem educados. No entanto, a ironia oferece o seu avesso, a oligarquia, ou seja, governo de poucos em benefício próprio, onde não pode habitar os “bons sentimentos”. Não é à toa que a voz cáustica, violenta e irritadiça de Maffesoli nos convida ao reconhecimento de um autoflagelo, porquanto, infelizmente, é perigoso não ter o “cheiro da matilha” (MAFFESOLI, 2009, p. 26) acadêmica:

Os instrumentos de controle, hoje em dia, estão um pouco mais "civilizados”. É verdade que as bancas de seleção universitária, [...] não condenam mais à fogueira, mas trabalhando de uma maneira tão dissimulada quanto eficiente, não qualificam, impedem a publicação, elaboram a conspiração do silêncio, excluem de qualquer expressão pública aqueles que não têm o cheiro da matilha (itálicos acrescidos).

A propriedade "matilha” da Academia-matilha representa a comunidade científica, instituída em universidades com suas pesquisas na produção do conhecimento (quando há conhecimento e não paráfrase); enfim, uma comunidade que consiste no corpo de cientistas, com suas relações e interações, normalmente dividida em subcomunidades, ou seja, cada uma 
trabalhando em um campo particular dentro da ciência. No entanto, a inteligibilidade, sendo o vetor constitutivo da identidade acadêmica, transforma essa própria inteligibilidade em majestade provida de vaidade exacerbada: “Somos capazes de 'ver roupas mágicas' apenas para sermos 'inteligentes' aos olhos dos outros, mesmo que isso nos torne ridículos” (REIS, 2006, p. 4). E, nessa exacerbação da vaidade que nos leva a ser comparados a "matilha”, a relação entre vida comum e ciência se esfacela. Nega-se a potência do vitalismo em prol do exercício do poder e da política. Em negando o vitalismo, nesse espaço, constituem-se “tribalismos” (MAFFESOLI, 2006) como motivo de identidade e de pertença a um grupo, que se configuram por articulações de forças, em que as de "poder” anulam as "potências” sociais que ali poderiam estar circulando.

A crítica violenta de Maffesoli chega à derrisão, ou seja, à “composição de [...] traços físicos, práticas presumidas, pretexto para formulações deselegantes, jogos de contraposição [que] ferem a manutenção da existência” (COURTINE apud MARTINS FERREIRA, 2006, p. 147), porquanto a derrisão vem "qualificar e desqualificar os conteúdos, medir seu impacto, soldar seus efeitos”. Instaura-se, assim, a dicotomia entre o divino acadêmico e o humano mortal da vida comum, como se a prática científica fosse apropriação de deuses olímpicos que não fazem mais parte do mundo dos simples mortais. Como diz Maffesoli (2009, p. 95),

para responder ao descompromisso e ao recuo, cuida-se da imagem. Falase mais à paixão do que à razão, e, quando das reuniões, o espetáculo de variedades é muito mais importante do que o discurso da personalidade política, que frequentemente deve contentar-se com o papel da vedete do teatro rebolado (itálicos acrescidos).

Além disso, Maffesoli (2009, p. 22) também denuncia o estabelecimento de uma ordem imposta à produção científica:

[...] quando alguém acredita, com toda boa-fé, estar propondo uma análise original, não faz mais do que servir uma sopa requentada, talvez temperada com algumas côdeas de pão de sua própria fatura. No conjunto, nada de muito apetitoso. [...] Tudo isso é de um tal conformismo que qualquer espírito, por pouco informado que seja, esforça-se por desobedecer as imposições das patronesses que as proferem (itálicos acrescidos).

Segundo a filosofia desse pensador, muitas vezes, seria ideal um recuo de determinadas políticas, como forma de reabilitar o vitalismo humano que parece estar sendo massacrado no espaço da intelligentsia (MAFFESOLI, 2006), que, isolado no tatame de lutas políticas de sua tribo, não se integra aos movimentos das potências revitalizadoras da sociedade em que habita.

Na realidade, nesta guerra, teríamos quatro categorias que constituiriam um par duplo: poder/ política versus potência/vitalismo. De um 
lado, no duplo poder-política não se pode delinear qual é a locomotiva de seus movimentos, porquanto entraríamos na velha história: Quem vem primeiro? O ovo ou a galinha? Poder se estabelece pelo jogo político e é no jogo político que o poder se instaura. Ambos semeiam simultaneamente o terreno fértil de atuação, com suas regras, acordos e combinações da matilha. De outro lado, o par potência e vitalismo humanos se completam e se amalgamam para uma perspectiva compreensiva e ad infinitum do dia a dia. E o paradoxo que se estabelece entre o par duplo - poder e política / potência e vitalismo - está no esquecimento vaidoso de que tal par são encenações que só podem montar o seu palco se os atores estiverem em vida. Ou melhor, querendo ou não, a pessoa-ator formador da ciência respira o vitalismo social, que, ao negá-lo, exclui as potências que poderiam nutri-lo. Aí, talvez, a construção da grande aporia do poder acadêmico, já que “competência e apetência caminham lado a lado” (MAFFESOLI, 2005, p. 29), ou seja, o saber científico (competência) é construído por pulsão vital (apetência); afinal o cientista reside no exterior social que sobrevive pela potência intrínseca.

\section{Considerações Finais}

Da tensão à guerra na academia e entre acadêmicos, o termo "epistemicídios” (SANTOS, 2006, p. 60) revela justamente um “paradigma epistemológico assente numa versão extrema de universalismo antidiferencialista", em que as diferenças de conhecimento e de objetos de saber são excluídos em prol da hegemonia da quantidade de celulose escrita e da abstração científica. O sistema inclusivo só admite a quantidade e abstração teórica. De ambos os lados um dizer irônico: - Publico, logo existo.

Talvez precisemos ler ou reler O Deus de Pequenas Coisas (ROY, 1998) para aprender com Rahel e Estha ${ }^{8}$ : eles descobrem que as coisas podem mudar num só dia, que as vidas podem ter seu rumo alterado e até assumir novas formas. São representantes do vitalismo geridos pela potência cotidiana. É uma obra que justamente nos mostra que os olimpos do absoluto não têm lugar na potência social, local dos mais ínfimos e frágeis pormenores.

Junto com Rahel e Estha, intervenho contra a cisão que se estabelece entre academia e saber comum. Se Beaudrillard (1985) se refere à massa silenciosa da sociedade como "eletricidade estática, não poderia esta mesma massa não poderia classificar a academia como “eletricidade estática”? Se aceitarmos a inversão das lentes, os pesquisadores e o saber científico se constituiriam de uma massa desconhecida e silenciosa pelos simples mortais. De tanto se autovalorar pela inteligibilidade, o acadêmico põe a venda nos olhos para a vida comum, esquecendo as águas dos rios da vida que os alimentam. Essa reinterpretação de “eletricidade estática” explicaria a cisão entre a nobreza científica em detrimento do lixo cotidiano, pois simbiotiza
${ }^{8}$ Prêmio Booker Prize de 1997, este é o livro de estreia da autora. Conta a história de dois gêmeos de sete anos cuja vida é transformada por um evento trágico. Como pano de fundo, a cultura indiana. Já traduzido para dezoito línguas. 
dois sentidos que, em princípio, constituem uma aporia. Como "eletricidade”, que pressupõe movimento, pode ter o atributo "estático”, algo que não se mexe? Por que não sermos uma eletricidade elétrica, ou seja, aderir ao vitalismo das potências que podem traduzir conhecimento, quebrando o silêncio da ciência?

O universo do paradoxo se expande, pois alguns pensadores, inclusive Einstein, Maffesoli e Rejagopalan, lutam pelas potências que deveriam habitar a ciência. Mas a aporia manifesta-se, pois a crítica precisa do fetiche para combatê-lo. A expressão na citação anterior de Einstein - substância essencial - tenta deslocar o centro do saber pelo processo de "renversement" (Derrida, 1999), ou melhor, apontar o que foi recalcado e valorizá-lo: decentramento da realeza olímpica da ciência, como um lugar excludente do saber comum. Será que a relação entre ciência e saber comum é (ou ainda só é) uma questão do “indecidível” (1999)? Seja qual for o caminho do decentramento, evitemos a já mencionada expressão de Boaventura Santos (2006, p. 60), “epistemicídios” (epistem(e) + (su)icídios), e encaremos o conhecimento como "condições de possibilidade da ação humana projetada no mundo” (p. 77), condições de possibilidade transformadas no vitalismo das potências que todos temos dentro de nós. Um conhecimento deste tipo é relativamente imetódico, constitui-se a partir de uma pluralidade metodológica” (p. 77), ou seja, o pesquisador deve fazer da produção do conhecimento um percurso de inovação, permitir-se a transgressões metodológicas, cujo processo discursivo resulte em uma "personalização do trabalho científico" (p. 79). A paráfrase e o amontoado do saber atendem ao estilo unidimensional, pois a dinâmica do conhecimento está na possibilidade diferencialista.

Parece-nos que esta guerra está muito mais para políticas de representação, tanto da identidade do sujeito acadêmico, quanto do movimento do conhecimento. O pesquisador se vê dentro de um stock identitário em que uma das identidades é assumida, ou de produzir papel, ou de estar no mundo da paráfrase, ou estar submisso a teorias, ou ser um livre pensador, ou ser um pensador comedido ou ter direito a uma pesquisa refletida, e assim por diante. E diante de tais identificações acadêmicas, muitas vezes uma das identidades é reivindicada pelas circunstâncias do salve-se-quem-puder carreirista. E nas circunstâncias do salve-se-quem-puder emerge o jogo político: se o pesquisador se mantém no centro da produção de paráfrase, dá-se a exclusão do conhecimento, mas se o pesquisador não aderir à quantidade pode ser ele o excluído. Eis o corredor que atravessamos no campo universitário, em que acadêmicos-pesquisadores-cientistas, ciência e vida se imiscuem em um embaralhamento que talvez possa representar o mundo acadêmico em que vivemos em nosso cotidiano. Esperamos que todo esse embaralhamento não pare em uma "fábrica de automóveis" (GONÇALVES FILHO, 2007), que o "número de publicações [não se] perpetrem em papel” (WATERS, 2006), que a "região sombria da pesquisa acadêmica” (2006) 
abra a porta à luz do conhecimento e que se apague o "cheiro da matilha" (MAFFESOLI, 2009).

\section{Referências}

Baudrillard, Jean. À Sombra das Maiorias Silenciosas, o Fim do Social e o Surgimento das Massas. Tradução de Suely Bastos. São Paulo: Brasiliense, 1985.

BOURDIEU, Pierre. Homo Academicus, Paris: Minuit, 1984.

DASCAL, Marcelo. Pragmatics and philosophy of mind. Amsterdam: John Benjamins, 1983.

DERRIDA, Jacques. Gramatologia. Tradução de Miriam Schnaiderman e Renato Janine Ribeiro. São Paulo, Perspectiva, 1999.

GONÇALVES FILHO, Antonio. O editor que não quer publicar pelo bem da ecologia, Lindsay Waters, da Harvard University Press, critica colegas acadêmicos e sugere maior rigor na hora de lançar um livro. Controvérsia Blog, p.1-7, 16 de setembro de 2007. Disponível em: www.controversia. com.br. Acesso em: 21 set. 2011 .

HALL, Stuart. A identidade cultural na pós-modernidade. Tradução de Tomas Tadeu da Silva e Guacira Lopes Louro. Rio de Janeiro: DP\&A, 2000.

KANT, Immanuel. Crítica da razão pura. Os Pensadores. Tradução de Manuela Pinto dos Santos e Alexandre Fradique Morujão. São Paulo: Abril, 1978.

MAFFESOLI, Michel. A Republica dos Bons Sentimentos. Tradução de Ana Goldberger. São Paulo: Iluminuras/Observatório Itaú Cultural, 2009.

MAFFESOLI, Michel. $\mathbf{O}$ tempo das tribos. $\mathbf{O}$ declínio do individualismo nas sociedades de massa. 4. ed. Tradução de Maria de Lourdes Menezes. Rio de Janeiro/São Paulo: Forense Universitária, 2006.

MAFFESOLI, Michel. Elogio da razão sensível. Tradução de Albert Cristophe Migueis. Petrópolis/Rio de Janeiro, Brasil: Vozes. 2005.

MARTINS FERREIRA, Dina Maria. Identidade feminina no espaço político: percurso simbólico na ecologia da linguagem. In: RAJAGOPALAN, Kanavillil e (Orgs.). Políticas em linguagem: perspectivas identitárias. São Paulo: Editora Mackenzie, 2006. p. 277-298.

ORTEGA Y GASSET, Jose. Meditaciones del Quijote. Madrid: Allianza, 1967.

RAJAGOPALAN, Kanavillil. Por uma linguística crítica: linguagem, identidade e a questão ética. São Paulo: Parábola, 2003. 
REIS, Humberto A roupa nova do rei, reflexões sobre o que não queremos ver. 2006. Disponível em: <www.hrconsultoria.com.br>. Acesso em: 23 jun. 2009.

RIBEIRO, Ana Elisa. Resenha - Walters, Lindsay. Inimigos da esperança. Publicar, perecer e o eclipse da erudição. Tradução Luiz Henrique de Araújo Dutra. São Paulo. UNESP 2006. Hipertextus. Revista Digital, 2, 2009. Disponível em: <www.hipertextus.net>. Acesso em: 21 dez. 2011. ROY, Arundathi. O deus das pequenas coisas Tradução de José Rubens Siqueira. São Paulo: Companhia das Letras,1998.

SANTOS, Boaventura de Souza. Um discurso sobre as ciências. 4. ed. São Paulo: Cortez, 2006.

SENNET, Richard. A corrosão do caráter. Tradução de Marcos Santarrita. Rio de Janeiro: Record, 2001.

SOKAL, Alan; BRICMONT, Jean. Imposturas intelectuais: o abuso da ciência pelos filósofos pós-modernos. Tradução de Max Altaman. Rio de Janeiro: São Paulo: Record, 1999.

TAGEBLATT, Berlim. Veja o que Einstein pensava sobre a relevância da divulgação científica. Jornal de Ciência e Tecnologia, p.1-4, ago. 2005.

WATERS, Lindsay. Inimigos da esperança: publicar, perecer e o eclipse da erudição. Tradução de Luiz Henrique de Araújo Dutra. São Paulo: Ed. UNESP, 2006.

Recebido em agosto/2018.

Aceito em janeiro/2019. 